\title{
Always on my mind: The impact of relational ambivalence on rumination upon
}

\section{supervisor mistreatment}

\begin{abstract}
Often viewed as a self-regulatory impairment (Thau \& Mitchell, 2010), rumination describes the repeated pondering of an offense (Caprara, 1986). The current study predicts that employees high in relational ambivalence with supervisors, or who "maintain both a positive and negative attitude toward their supervisor," are more likely than those in positive or negative relationships to ruminate over a supervisor-induced psychological contract violation (S-I PCV). By use of a 10-day diary study, this study reveals differences in the moderating role of relationship quality with supervisors (i.e., positive, negative, or ambivalent) on S-I PCV and rumination. More specifically, relational ambivalence with supervisors positively moderated the relationship between S-I PCV and rumination, whereas positive and negative relationships with supervisors both negatively moderated this relationship.
\end{abstract}

Keywords: relational ambivalence, psychological contract violation, rumination, social exchange 


\section{Always on my mind: The impact of relational ambivalence on rumination upon supervisor mistreatment}

Supervisors play a critical role in determining the direction, coaching and evaluation that employees receive (Shoss, Eisenberger, Restubog \& Zagenczyk, 2013) and the nature of this relationship influences the resources employees obtain and their contributions to the organization. Given the importance of the supervisor, it is not surprising that significant research attention has been given to exploring the consequences of the employee-supervisor relationship on important organizational outcomes. Meta-analytic findings establish beneficial consequences of positive relationships with supervisors (Gerstner \& Day, 1997) and detrimental consequences of negative relationships (Skarlicki \& Folger, 1997; Mitchell \& Ambrose, 2007; Biron, Brun \& Ivers, 2008). For example, leader-member exchange (LMX) is positively related to citizenship behaviors (Vidyarthi, Liden, Anand, Erdogan \& Ghosh, 2010); perceived supervisory support (PSS) is positively related to in-role and extra-role performance (Shanock \& Eisenberger, 2006); abusive supervision is negatively related to job satisfaction and job performance and positively related to workplace deviance (Tepper, 2007). The majority of this research examines positive and negative relationships independent of each other and neglects that sometimes organizational relationships are neither exclusively positive or negative, but both (Ashforth et al., 2014; Kreiner \& Ashforth, 2004). An employee may have a relationship with their supervisor that vacillates between positive and negative experiences (e.g., being commended for good work and yelled at for something else).

Existing literature takes this into account by examining how positive and negative interactions with a supervisor interact to explain employee outcomes. Specifically, this strand of research seeks to determine whether supportive supervision buffers or exacerbates the negative effects of supervisory undermining on employees. Duffy, Ganster \& Pagon (2002) 
found that employees who perceive their supervisor as providing high support and high undermining engaged in greater counterproductive behaviors and had lower levels of commitment and well-being. Subsequent empirical work demonstrates that whether supervisor support attenuates or accentuates the effects of supervisory undermining is contingent upon an employee's self-esteem and quality of work life (QWL); for employees with high self-esteem, supervisor support buffered the adverse effects and exacerbated the effects when employees had low self-esteem; for employees with high QWL, supervisor support buffered the adverse effects and for employees with low QWL, supervisor support exacerbated the effects (Nahum-Shani, Henderson, Lim \& Vinokur, 2014).

We set out to contribute to understanding positivity and negativity in employeesupervisor relationships but from a different starting point. First, drawing on close relationship research (e.g., Fincham \& Linfield, 1997), we argue that relationships characterized by positive and negative interactions are ambivalent relationships. Thus, rather than examining the positive buffering effects of negative interactions, we suggest the combined presence of both create an overall ambivalent relationship. It is the effects of the overall relationship quality that are the focus here. This perspective highlights that both positive and negative experiences occur within relationships and suggest that it is probable if not common - for individuals to develop competing attitudes towards another individual. Whereas past research has begun to understand ambivalence in the context of organizational change (Piderit, 2000), corporate crime (Vadera \& Pratt, 2013), decision making (Plambeck \& Weber, 2009), and organizational commitment (Pratt \& Rosa, 2002), we know little about ambivalence in employee-supervisor relationships in contrast to positive and negative relationships.

Second, how does this relational experience fit within current conceptualizations of positive and negative relational quality? Close relationships research has found that many 
relationships are comprised of a certain degree of both love and hate (e.g., Coser, 1966; Fincham \& Linfield, 1997). A more comprehensive view of relational quality should take into account relationships that are both positive and negative in addition to those that are positive or negative. We consider this research a first step into this direction by exploring the potential for variation in the ways in which positive, negative, and ambivalent employees react to negative emotional events with their supervisor. We examine rumination as a potential outcome because past research suggests ambivalence heightens attention to subsequent attitude-defining cues (Maio, Esses, \& Bell, 1996) and because ambivalence arouses a consistency seeking motivation (Nordgen, Harreveld, \& Van der pligt, 2005).

By empirically examining how employees' respond to the experience of relational ambivalence with their supervisor, we address a recent call for organizational research to examine employee responses to ambivalence that are created from specific organizational triggers (Ashforth et al., 2014). In this study, we explore the effect of employees' perception of relational ambivalence with their supervisor on rumination after a negative emotional event. We describe these negative emotional events as supervisor-induced psychological contract violations (S-I PCV) and add to Morrison \& Robinson's (1997) definition the organizational agent responsible for the psychological contract violation. Therefore, S-I PCV is defined as the emotional or affective state that employees experience after the cognition that one's supervisor has failed to meet one or more obligations within an employee's psychological contract. This definition coincides with the expectations that employees often generate with specific agents within their organizations - thereby making the contents and terms of the exchange slightly more palpable.

\section{Theory and Background of Hypotheses}


The extant literature captures a range of positive and negative employee-supervisor relationships such as leader-member exchange (Graen \& Cashman, 1975; Graen \& Scandura, 1987; Liden, Sparrowe, \& Wayne, 1997), perceived supervisor support (Kottke \& Sharafinski, 1988), interactional justice (Bies, 1986) abusive supervision (Griffen \& O’LearyKelly, 2004; Tepper, 2007) aggressive supervision (Schat, Frone, \& Kelloway, 2006), supervisor undermining (Duffy, Ganster, \& Pagon, 2002), and destructive leadership (Padilla, Hogan, \& Kaiser, 2007). These constructs capture relationship valuations that are either positive or negative but not both. Some employees may experience an amalgam of both positive (i.e., support) and negative (i.e., abuse) exchanges with their supervisor and consequently evaluate their relationship as ambivalent.

Ambivalence (literally meaning "both" "to be strong") is when an individual simultaneously holds favorable and unfavorable attitudes toward someone or something (Eagly \& Chaiken, 1998; Kaplan, 1972; Katz \& Hass, 1988). It is often described as having "mixed feelings" or being "torn between conflicting impulses." For example, an employee might experience ambivalence when her supervisor is good at introducing her to key players in their business but terrible at offering her proper feedback on her performance. Ambivalent attitudes, therefore, occur when an individual is inclined to give an attitude object comparably strong positive and negative valuations (Thompson, Zanna, \& Griffin, 1995). Individuals who are familiar with one another, such as the case with employees and their supervisors, should hold sufficient information on both positive and negative features of the relationship. If the employee has both positive and negative experiences, the resultant evaluation of that relationship will be ambivalence. Dissonance theory (Festinger, 1957) posits that holding two inconsistent thoughts at the same time is experienced as aversive. Ambivalence is considered by some to be a more intense form of cognitive dissonance, since the competing attitudes are derived from opposite extremes (Baek 2010; Ashforth et al., 2014). 
From its theoretical conception, ambivalence has been described as an aversive state that increases guilt, enhances self-doubt, generates anxiety, and weakens motivation (Katz et al., 1977; Wiegert, 1991). It produces tension, conflict and unpleasant emotions (Larsen, in press) and heightens an individual's attention to subsequent cues from attitudinal objects (Maio, Bell, \& Esses, 1996; Ashforth et al., 2014). Consequently, ambivalence arouses a consistency seeking motivation (Nordgren, van Harreveld, \& van der Pligt, 2006) in such a way that any new information helps to assuage an individual's feelings of dissonance. Ironically, the unpleasantness of such dissonance (Festinger, 1957; Cooper \& Fazio, 1984; Rudolph \& Popp, 2007) can be relieved irrespective of the constructive or destructive nature of subsequent events (Pratt \& Barnett, 1997; Kachadourian, Finchan \& Davila, 2005). Consequently, ambivalent individuals have been known to over-react to stigmatized persons in order to craft a more defined, and therefore less ambiguous status (Katz et al., 1977). For example, an employee holding an ambivalent attitude toward her supervisor might send a potentially job threatening, emotional email to her supervisor after her boss offends her. But does this propensity to overreact to negative events imply lack of thought?

\section{Ambivalence and Rumination}

Portrayed as an unconstructive method for coping, intrusion of thought, or rumination, is characterized by excessive self-reflection (Morrow \& Nolen-Hoeksema, 1990) and a repetitive focus on negative emotions (Nolen-Hoeksema, 1991, 2000) or transgressions (Caprara, 1986). Often depicted as a self-regulatory impairment (Thau \& Mitchell, 2010), it is also defined as the repeated pondering of an offense. Such consistent and unwanted intrusion of thought (Horowitz et al., 1979) impairs individuals by depleting their individual resources (Baumeister \& Heatherton, 1996; Oaten, Wiliams, Jones, \& Zadro, 2008; Wegner, 1994). This, inherently, makes it difficult for individuals to progress after experiencing an offense (McCullough, Bellah, Kilpatrick, \& Johnson, 2001). 
Rumination is likely to be a prominent feature amongst ambivalent individuals who experience negative emotional events with their supervisors. One reason for this could be related to the goal reconstruction that might be necessary when what we think and experience does not align with what we feel or know to be true (Carver \& Scheier, 1998). Acknowledging this could provoke a sense-making process that might materialize as rumination for two reasons: 1) employees are attempting to understand the actual state of the relationship and how it compares with where the employee wants the relationship to be, and 2) employees are considering the consequences that might arise when relationships with managers are poor. Therefore, the sense-making involved in trying to eliminate the discomfort associated with ambivalence (e.g., Do I react strongly and force this relationship into a negative state or somehow excuse my supervisor's behavior?) is likely to be the driving force behind employee rumination. It is for this reason that ambivalent individuals often find it difficult to forgive a wrongdoer after an offense (Kachadourian et al., 2005).

A related study found that intrusive thoughts are likely to occur when supervisors abuse their employees and when distributive justice is high (Thau \& Mitchell, 2010). This type of interactional effect mimics our definition of relational ambivalence since competing positive and negative relationship experiences (e.g., high distributive justice and abuse) coexist. Given that ambivalent individuals are well aware of the source of their ambivalence (Locke \& Braun, in 2009; Ashforth et al., 2014) and that ambivalence evokes an uncomfortable state (Katz et al., 1977; Nordgren et al., 2006), it is probable that a negative emotional event with an employee's supervisor would increase rumination. Therefore we predict:

Hypothesis 1: The relationship between a supervisor-induced psychological contract violation (S-I PCV) and rumination will be moderated by relational ambivalence such 
that the relationship between S-I PCV and rumination will be positive when employees are in an ambivalent relationship with their supervisor.

\section{Positive relationships and rumination}

It is generally believed that no matter how great the relationship, most employees will experience varying degrees of anger, sadness or resentment in response to a supervisor's failure to meet their expectations. However, the way in which employees deal with such negative emotion is largely contingent on the relationship itself. Employees that appraise their relationship with their supervisor as positive do so primarily because they have had mostly favorable experiences with their supervisor in the past. These consistencies in favorable treatment generate a repertoire of mutual respect, commitment and trust and often contribute to a perception of relational closeness (Blau, 1964; Cropanzano \& Mitchell, 2005). Consequently, employees that describe their relationship with their supervisor as being one of "higher quality" tend to have higher tolerance thresholds for broken promises and their reactions to injustices tend to be less severe (Tekleab et al., 2005). Dulac and his colleagues (2008) argue this is mostly due to the fact that individuals in higher quality relationships purposely interpret errors in the relationship with some degree of bias in an effort to avoid the dissonance associated with such paradox (e.g., I should not feel hurt by an individual who cares for me).

Commitment to a relationship also strengthens over time (e.g., McCullough et al., 1998; Bradfield \& Aquino, 1999; Fincham, 2000; Orth, 2004; Kidder, 2007). Commitment, in this sense, indicates concern for the interests of the partner and the relationship (Finkel et al. 2002, Rusbult et al. 1991, Van Lange et al. 1997). In such positive relationship conditions, a supervisor who violates an employee's psychological contract, though a departure from the well-established expectations of the relationship (Finkel et al., 2002), is likely to be forgiven. 
Forgiveness, in such cases, might be a method to preserve the balance associated with high quality relationships (Aquino, Tripp, \& Bies, 2001) or as a means to achieve certain goals within organizations (De Cremer, 2007). As a consequence of this commitment to the relationship, individuals are likely to engage in forgiveness as a means for restoration when the strength of a violation is high.

Although it is natural to want to retaliate when we are offended, Fincham (2000) says we are motivated by cognitive biases that allow certain individuals to be seen in a more positive light. He suggests, in doing so, we minimize others' faults and embellish their virtue. Comparably, McCullough et al. (2000) elaborate certain conditions under which this is particularly true and suggest individuals incur a greater motivation to preserve a relationship when the relationship consists of equally reciprocated resources, a long-term orientation, a merging of partner and self-interests, and a greater ease at interpreting a partner's injurious behavior. De Cremer (2007), on the other hand, suggests some individuals self-regulate their response to violations in order to achieve certain goals. Whatever the case, one can assume that when relationships with supervisors are regarded as positive, employees might have a strong desire to maintain this level of quality with such influential organizational members. Since previous exchanges within the relationship have served to construct the basis for a high quality relationship, it is unlikely employees in positive relationships with their supervisor will give too much thought to a supervisor's infrequent, negative behavior. Therefore we predict:

Hypothesis 2: The relationship between supervisor-induced psychological contract violation $(S-I P C V)$ and rumination will be moderated by an employee's positive valuation of the relationship such that the relationship between S-I PCV and rumination will be negative when employees hold positive valuations. 


\section{Negative relationships and rumination}

Employees who define their relationship with their supervisor as negative have done so because, when they examine the relationship on the whole, the negative experiences they have with their supervisor far outweigh the positive experiences. Interpersonal resources exchanged between the individuals are likely to have depleted, and it is possible that the relationship has become dysfunctional. This continual downward spiral is concomitant with non-forgiveness (Burt \& Knez, 1996), which yields outcomes such as animosity, hostility, anger, distrust, and conflict escalation (Aquino et al., 2003; Axelrod, 1984; Lewis \& Weigert, 1985; Luhrnann, 1979).

These employees often develop hopeless and transactional relationships with their supervisors, because they have lost the interpersonal aspects that nurture the relationship. The reciprocally exchanged resources of trust, loyalty, commitment, and support that typically sustain relationships (Gouldner 1960, Graen \& Uhl-Bien, 1995), are likely to have been replaced with resentment, ill will, and thoughts of revenge. For example, Shore, Tetrick, Lynch \& Barksdale (2006) argue that these types of impersonal relationships are defined by lower degrees of trust and investment and do not incorporate the long-term obligations created in stronger interpersonal relationships.

Therefore, when faced with [what is most likely a subsequent] supervisor-induced psychological contract violation, these employees are unlikely to take notice of their supervisor's consistently negative treatment. Instead, such experiences will most likely reinforce their already negative attitude towards the relationship. In such cases, ruminating about their supervisor's consistently bad behavior is unlikely, since they have already accepted the relationship as it is. Unlike ambivalent employees who tend to have a balance of positive treatment, employees who appraise their relationship with their manager as negative 
recognize the hopelessness of the relationship and accept the relationship for what it has become. Therefore, we predict:

Hypothesis 3: The relationship between supervisor-induced psychological contract violation (S-I PCV) and rumination will be moderated by an employee's negative valuation of the relationship such that the relationship between S-I PCV and rumination will be negative when employees hold negative valuations.

Please see Figure 1 below for the full research model.

Insert Figure 1 about here

\section{METHOD}

The purpose of this study was to examine the short-term ( 2 weeks) moderating effect of relationship quality (positive, negative, ambivalent) on the relationship between S-I PCV and rumination.

\section{Sample and Procedures}

Participants included 38 auditors (20 females, 18 males) working at a large bank in North America. The 38 employees worked in groups that were supervised by one of 20 different supervisors, which were part of a larger department of 165 people. The 38 focal participants completed 357 daily surveys over the course of a 2-week period. Participants' ages ranged from 28 to 63 years old $(M=46.9, \mathrm{SD}=9.08)$. This sample size of focal participants compares favorably with other field studies collecting daily observations from employees (e.g., Alliger \& Williams, 1993; Fuller et al., 2003; Scott \& Judge, 2006).

We recruited participants via an organizational contact. The study was described to 
participants as an examination of day-to-day interactions with supervisors. We contacted interested employees, and also gave an on-site presentation to explain the diary study instructions and parameters. All data were collected online using electronic surveys. After viewing an informed consent, participants were first instructed to provide background information relevant to the study (e.g., personality, age, gender). Two weeks later, participants were asked to complete a daily survey for a 2-week period, workdays only (i.e., Mondays-Fridays). To facilitate response rates during the daily diary portion of the study, we sent email reminders to participants at 8:30 am three times per week. The email reminders contained the link to the online survey. Participants were instructed to complete the daily survey at or near the end of their workday. The daily survey contained the measures of relationship quality (positive, negative, ambivalent), supervisor-induced psychological contract violation (S-I PCV), and rumination. In exchange for participating, participants received a chance to win $\$ 500$.

Thirty-eight employees originally volunteered for and ultimately participated in most of the study. Together, these employees completed 357 daily surveys across the 2-week period. We inspected timestamps collected in tandem with the daily surveys to assess whether participants adhered to the study instructions. This inspection revealed that all surveys were completed on workdays. This was largely because the survey was only open for 5 hours each evening and only on workdays (Monday - Friday). Twenty-three surveys from the analyses were not completed, leaving 357 daily surveys $(M=9.3$ daily surveys per employee). Given that each employee could complete a maximum of 10 surveys each (for a total of 380 daily surveys), this corresponds to a daily survey response rate of $93.9 \%$. The 357 daily surveys were completed between 4:30 pm and 9:30 pm. Finally, each employee was sent a specific link that would only work when accessed through his or her email. This ensured that the employee and not someone else completed the surveys. 


\section{Measures}

Control Variables. As stated in the previous section, some controls were obtained two weeks prior to the 10-day data collection period. In addition to age, gender and organizational tenure, we assessed state positive and state negative affect using items from the PANAS-X (Watson \& Clark, 1994). In order to reduce problems of retrospective recall (Robinson \& Clore, 2002), we collected “online" reports of affect each day by asking participants to indicate the extent to which they were experiencing each state "right now" using a scale $1=$ very slightly or not at all to $5=$ Extremely. Items comprising the positive affect scale included "calm," "at ease," "determined," and "alert." Items comprising the negative affect scale included "hostile," “angry," “sad," and “downhearted." Average coefficient alphas for these scales over the 10 days of data collection were $\alpha=.89$ for the positive affect scale and $\alpha=.76$ for the negative affect scale.

Relationship Quality. Given our interest in understanding ambivalent relationship valuation and its susceptibility to change, we created a three-item measure to capture this potential. Individuals were asked to report the overall quality of the relationship with their supervisor on that day. Response options included good, bad, or both good and bad. Employees reported on a 5-point Likert scale, ranging from strongly disagree to strongly agree, their overall attitude toward the relationship on that day.

Supervisor-Induced Psychological Contract Violation (S-I PCV). To assess whether or not employees had experienced emotional harm associated with a supervisor's failure to meet their expectations, we slightly altered the global measure used to capture psychological contract violation (Rousseau, 1989; Morrison \& Robinson, 1997). By replacing 'organization' in the original items with 'supervisor' for this study, we were able to specifically identify supervisors as the agents responsible for employee emotional harm. 
Therefore example items included "Today, I feel extremely frustrated by how I have been treated by my supervisor" and "Today, I feel a great deal of anger toward my supervisor." Employees responded using a 5-point Likert scale ranging from strongly disagree to strongly agree. Average coefficient alpha for this scale over the 10 days of data collection was $\alpha=.92$.

Rumination. Rumination was captured using seven items from the Impact of Events Scale (Horowitz et al., 1979), adapted to specific events (e.g., McCullough et al., 2001) and here to the supervisor's behaviors. Items included "I thought about my supervisor's behavior when I didn’t mean to" and "I had trouble falling asleep or staying asleep because of pictures or thoughts about my supervisor's behavior that came to my mind." One other study has adapted this scale in this way (Thau \& Mitchell, 2010), and reported significant findings. Respondents indicated how often they experienced these thoughts over the past 24 hours using a 4-point Likert scale ranging from not at all to often. Average coefficient alpha for this scale over the 10 days of data collection was $\alpha=.88$.

\section{RESULTS}

Given the multilevel nature of our data, we used hierarchical linear modeling (HLM; Raudenbush \& Bryk, 2002) to test the relationships among participants' perceptions of relationship quality, S-I PCV, and rumination. HLM consists of a series of regression equations that take into account the nonindependence in data that arises from having participants contribute multiple data points across time and from having participants cluster in groups. In the current study, the data comprises two levels because days are nested in employees. The first level, or Level 1, captures variance within employees and consists of the repeated, within-individual measures taken daily of employees' reports of relationship quality (positive, negative, ambivalent), S-I PCV, and rumination. The second level, or Level 2, captures variance between individuals within groups. 
Following the recommendation of Hofmann, Griffin, and Gavin (2000), we centered the Level 1 predictor at participants' means. Individual-mean centering is preferred when testing within-individual relationships because it removes all between-individual variance from the Level 1 variables. By centering variables relative to each participant's mean, each participant's overall mean for a given variable, across the days of data collection, becomes zero; hence, the variance between individuals becomes zero. As a result, the within-individual relationships are not confounded by individual differences such as response tendencies. The Level 2 control variables were grand-mean centered. Finally, given that research has revealed age and gender differences in relationship valuations, such that women tend to be more empathic than men (Eisenberg, 2000) and older (more experienced) individuals tend to experience greater ambivalence (Thompson, Zanna, \& Griffin, 1995), we controlled for employee age and gender when examining the direct effects of the analyses. Job type was controlled by design because employees and their supervisors all worked for the same company and in the same occupation (auditing).

Descriptive statistics and correlations are shown in Table 1. Correlations are at the within-individual level and are calculated by standardizing the regression coefficient obtained in HLM analyses between one predictor and one criterion at Level 1. As shown in Table 1, at the within-individual level, relational ambivalence was significantly correlated with age $(r=-$ $.29, \mathrm{p}<.01)$, organizational tenure $(\mathrm{r}=-.32, \mathrm{p}<.01)$, positive affect $(\mathrm{r}=-.18 \mathrm{p}<.01)$, negative affect $(\mathrm{r}=.13, \mathrm{p}<.05)$, S-I PCV $(\mathrm{r}=.28, \mathrm{p}<.01)$, positive relationship quality $(\mathrm{r}=$ $.42, \mathrm{p}<.01)$, negative relationship quality $(\mathrm{r}=.50, \mathrm{p}<.01)$ and rumination $(\mathrm{r}=.13, \mathrm{p}<.01)$.

Insert Table 1 about here

In this study, we proposed that employee perceptions regarding the type of 
relationship they maintain with their supervisors (positive, negative, and ambivalent) would moderate the relationship between S-I PCV and rumination. Full maximum likelihood estimation was used so that deviance tests, analogous to chi-square tests in structural equation modeling or R-square difference tests in OLS regression, could be conducted to indicate effect size (Raudenbush \& Bryk, 2002). Model deviance is equal to two times the negative log-likelihood and the difference in deviance between two models has a chi-square distribution with degrees of freedom equal to the difference in the number of parameters between the two models. Therefore, to test Hypotheses 1-3, we regressed the interaction effect of relationship quality (positive, negative, and ambivalent) and S-I PCV on rumination using HLM. As shown in Table 2, relational ambivalence positively moderated the relationship between S-I PCV and rumination $\left(\gamma_{120}=.22 p<.01\right)$, positive relationship quality negatively moderated the relationship between S-I PCV and rumination $\left(\gamma_{100}=-.23 p<.01\right)$, and negative relationship quality negatively moderated the relationship between S-I PCV and rumination $\left(\gamma_{110}=-.14 p<.10\right)$. Thus, Hypotheses $1-3$ were supported. Figures 2,3 , and 4 illustrate the moderating effect of ambivalent, positive, and negative relationship quality on the S-I PCV- rumination relationship, respectively.

Insert Table 2 about here

Insert Figure 2 about here

Insert Figure 3 about here 
Insert Figure 4 about here

\section{DISCUSSION}

In line with other researchers expressing the need to account for ambivalence in organizations (e.g., Kreiner \& Ashforth, 2004; Locke \& Braun, 2009; Oreg \& Sverdlik, 2010), the current paper sought not only to gain a more realistic understanding of relationship quality by acknowledging the role of ambivalence, but also to test how relationship quality (including ambivalence) influences the way in which employees react to negative emotional events like that of a supervisor-induced psychological contract violation (S-I PCV).

What we discovered was reactions to supervisor maltreatment do vary according to employee perceptions of the relationship. Indeed, our study revealed that ambivalent employees were more likely than those in positive or negative relationships to ruminate about negative treatment from their supervisor. Whether they are ruminating about how to make the relationship better, or why their manager has treated them so poorly (again), it seems ambivalent employees think about their manager's action whether they want to or not. Either way, rumination seems to be a detrimental coping response for the employee and the organization. Empirically, ruminating over negative events has been found to limit forgiveness capabilities, since the event tends to prime the negative component of ambivalence (Kachadourian et al., 2005). Consequently, ruminating over a supervisorinduced psychological contract violation is likely to limit organizational performance, because it impairs employee coping ability (Thau \& Mitchell, 2010).

This research also adds an interesting perspective to the psychological contract literature. First, the vast majority of psychological contract studies have been cross-sectional 
and very few have examined the psychological contract on a daily basis (Conway \& Briner, 2005). In addition, there have been no studies [to our knowledge] that examine the direct role of supervisors in violating psychological contracts. Finally, the inclusion of relational ambivalence in psychological contract research is completely new. Since ambivalence is known to heighten individual sensitivity to attitude confirming cues (Katz et al., 1977; Nordgren et al., 2006; Mikulincer et al., 2010), we assumed that events with supervisor would be highly salient for relationally ambivalent employees. Accordingly, negative events like psychological contract violations would be more noticeable to these employees. As this was particularly true in our study, we feel it is important for psychological contract theorists to recognize that there may be residual effects of violation that go beyond the employee's immediate behavioral response.

Finally, the results suggest that rumination after a violation is less likely for employees who maintain either positive or negative relationships with their supervisors. This is most likely because employees who valuate their relationship as positive are more likely to excuse their manager's bad behavior or recognise that their manager will somehow make it up to them in the future (Rousseau, 1995). On the other hand, employees holding negative perceptions about the relationship probably do not ruminate about a supervisor-induced psychological contract violation because this type of bad behavior is consistent with their already negative appraisal of the relationship. As mentioned previously, even consistent negative treatment is less taxing on employees than inconsistent treatment (Pratt \& Barnett, 1997; Kachadourian et al., 2005).

\section{Limitations and Implications for Future Research}

Some limitations within this study should be noted. First, the within-individual relationships among the study variables were based on employee-reported responses, raising 
the possibility that the within-individual relationships are inflated by common source variance. Given their perceptual nature, however, these variables are perhaps best assessed via self-report, as perceptions of the relationship are rather subjective assessments not easily observed by others. In addition, because we centered the daily measures relative to participants' means, we avoided several sources of common-method variance, such as response tendencies and trait affectivity. Indeed, state and trait affectivity were modeled as control variables in our analyses. However, centering does not remove all sources of common method variance, such as implicit theories of how measures interrelate, concurrence of measures, and common scale formats (Podsakoff, MacKenzie, Lee, \& Podsakoff, 2003). Thus, the results should be interpreted with this issue in mind. Other limitations center on our choice of measures. Given the demanding nature of the diary design, some of the daily measures (relationship valuation, PA, NA) were truncated for practical purposes. Despite this, these measures demonstrated acceptable reliabilities.

We believe this paper takes a step forward in advancing the way in which we think about employee-supervisor relationships in organizations. We attempted to carry forward a concept already recognized by close-relationship scholars in order to give meaning to employee-supervisor relationships that were previously difficult to define. By including this new relational framework, this paper demonstrated that the consequences for relational ambivalence were different from the more often-researched positive or negative relationship types. This paper has shed new light on the way in which relationships with supervisors function, and it has contributed to the theoretical understanding of exchange relationships by, perhaps, giving meaning to the grey area on relationship quality scales. In doing so, it has explored quantitative differences in outcomes over time and captured these differences using experience sampling. 
Our paper demonstrated the short-term effects of relationship perceptions on rumination after a S-I PCV. In addition to studying the long-term effects of these variables, future studies should target other outcome variables that might help to differentiate ambivalence from positive and negative relational frameworks. For instance, given the discomfort ambivalence tends to create, it would be interesting to explore whether and how ambivalent employees shift their relationship perceptions over time. Additionally, other outcome variables such as job satisfaction, turnover intent, and commitment would also be interesting to explore. While we suggest ambivalence is derived from inconsistent interactions with supervisors, future research might also address other potential antecedents. For example, it could be plausible that personality or attachment styles contribute to ambivalent relationships in organizations. At any rate, as with any new construct, the possibilities for new ideas are limitless. Therefore, by introducing relational ambivalence to this literature, we hope new and exciting paths for employee-organization relationship scholars have been charted. 


\section{REFERENCES}

Alliger, G. M., \& Williams, K. J. (1993). Using signal-contingent experience sampling methodology to study work in the field: A discussion and illustration examining task perceptions and mood. Personnel Psychology, 46, 525-549.

Aquino, K., Grover, S. L., Goldman, B., \& Folger, R. (2003). When push doesn't come to shove Interpersonal forgiveness in workplace relationships. Journal of Management Inquiry, 12(3), 209-216.

Aquino, K., Tripp, T. M., \& Bies, R. J. (2001). How employees respond to interpersonal offense: The effects of blame attribution, offender status, and victim status on revenge and reconciliation in the workplace. Journal of Applied Psychology, 86, 52-59.

Ashforth, B.E., Rogers, K.M., Pratt, M.G., \& Pradies, C. (2014). Ambivalence in organizations: A multilevel approach. Organization Science, 25, 1453-1478.

Axelrod, R. (1986): 'The Evolution of Norms", American Political Science Review, Vol. 80, 1095-1111.

Baek, Y. M. (2010). An integrative model of ambivalence. The Social Science Journal, 47(3), 609-629.

Baumeister, R. F., \& Heatherton, T. F. (1996). Self-regulation failure: An overview. Psychological Inquiry, 7, 1-15.

Bies, R. J. (1986). Identifying principles of interactional justice: The case of corporate recruiting. In R. J. Bies (Chair), Moving beyond equity theory: New directions in research on justice in organizations. Symposium conducted at the meeting of the Academy of Management, Chicago.

Blau, P. (1964). Exchange and power in social life. New York: Wiley.

Biron C., Brun J.-P., Ivers H. (2008) Extent and sources of occupational stress in university staff. Work, 30, 511-522.

Bradfield, M., \& Aquino, K. (1999). The effects of blame attributions and offender likableness on forgiveness and revenge in the workplace. Journal of Management, 25(5), 607-631.

Burt, R. S., \& Knez, M. (1996). Trust and third-party gossip, In R. M. Kramer \& T. R. Tyler (Eds.), Trust in organizations: 68-89. Thousand Oaks, CA: Sage.

Caprara, G.V. (1986). Indicators of aggression: The dissipation-rumination scale, Personality and Individual Differences, 17: 23-31.

Carver, C.S., \& Scheier, M.F. (1998). On the self-regulation of behavior. New York: 
Cambridge University Press.

Conway, N. and Briner, R. (2005) Understanding Psychological Contracts at Work: A Critical Evaluation of Theory and Research. Oxford University Press, Oxford.

Cooper, J., \& Fazio, R. H. (1984). A new look at dissonance. Advances in experimental social psychology, 17, 229-268.

Coser, R. L. (1966). Role distance, sociological ambivalence, and transitional status systems. American Journal of Sociology, 72:173-187.

Cropanzano, R., \& Mitchell, M. S. (2005). Social Exchange Theory: An Interdisciplinary Review. Journal of Management, 31, 874-900.

De Cremer, D. (2007). Advances in the psychology of justice and affect. Greenwich, CT: Information Age Publishing.

Duffy, M. K., Ganster, D., \& Pagon, M. (2002). Social undermining in the workplace. Academy of Management Journal, 45, 331-351.

Dulac, T., Coyle-Shapiro, J. A-M., Henderson, D., and Wayne, S. J. (2008). Not all responses to breach are the same: the interconnection of social exchange and psychological contract processes in organizations, Academy of Management Journal, 5 (6):, 1079-1098.

Eagly A.H., Chaiken S. (1998). Attitude structure and function. In The Handbook of Social Psychology, ed. DT Gilbert, ST Fiske, 2:269-322. Boston: McGraw-Hill. 4th ed.

Eisenberg, N. (2000). Emotion, regulation, and moral development. Annual Review of Psychology, 51, 665-697.

Festinger, L. (1957). A theory of cognitive dissonance. Evanston, IL: Row Peterson.

Fincham, F. D. (2000). The kiss of the porcupines. From attributing responsibility to forgiving. Personal Relationships, 7, 1-23.

Fincham, F. D., \& Linfield, K. J. (1997). A new look at marital quality: Can spouses 
feel positive and negative about their marriage? Journal of Family Psychology, 11, 489-502.

Finkel, E.J., Rusbult, C.E., Kumashiro, M., \& Hannon, P.A. (2002). Dealing with betrayal in close relationships: Does commitment promote forgiveness? Journal of Personality and Social Psychology, 82, 956-974.

Fuller, J. A., Stanton, J. M., Fisher, G. G., Spitzmuller, C., Russell, S. S., \& Smith, P. C. (2003). A lengthy look at the daily grind: Time series analysis of events, mood, stress, and satisfaction. Journal of Applied Psychology, 88, 1019-1033.

Gerstner, C. R., \& Day, D. V. (1997). Meta-analytic review of leader-member exchange theory: Correlates and construct issues. Journal of Applied Psychology, 82, 827844.

Gouldner, A.W. (1960). The norm of reciprocity: a preliminary statement. American Sociological Review, 25(2), 161-178.

Graen, G., \& Cashman, J. (1975). A role-making model of leadership in formal organizations: A developmental approach. In J. G. Hunt \& L. L. Larson (Eds.), Leadership frontiers (pp. 143-166). Kent, OH: Kent State University Press.

Graen, G. B., \& Scandura, T. A. (1987). Toward a psychology of dyadic organizing. Research in Organizational Behavior, 9, 175-208.

Graen, G. B., \& Uhl-Bien, M. (1995). Relationship-based approach to leadership: Development of leader-member exchange (LMX) theory of leadership over 25 years: Applying a multi-level multi-domain perspective. Leadership Quarterly, 6, 219-247.

Griffin, R. W., \& O’Leary-Kelly, A. (2004). The dark side of organizational behavior. San Francisco: Jossey-Bass.Harlos, K. P., \& Pinder, C. C. (2000). Emotion and injustice in the workplace. In S. Fineman (Ed.), Emotion in organizations (pp. 255276). Thousand Oaks, CA: Sage Publications.

Horowitz, M., Wilner, N. \& Alvarez, W. (1979). Impact of Events Scale: A measure of subjective stress. Psychosomatic Medicine, 41, 209-218.

Hofmann, D. A., Griffin, M. A., \& Gavin, M. B. (2000). The application of hierarchical 
linear modeling to organizational research. In K. J. Klein \& S. W. J. Kozlowski (Eds.), Multilevel theory, research, and methods in organizations: foundations, extensions, and new directions (pp. 467-511). San Francisco: Jossey-Bass.

Kachadourian, L. K., Fincham, F. D., \& Davila, J. (2005). Attitudinal ambivalence, rumination and forgiveness of partner transgressions in marriage. Personality and Social Psychology Bulletin, 31, 334-342.

Kaplan, K. J. (1972). On the ambivalence-indifference problem in attitude theory and measurement: A suggested modification of the semantic differential technique. Psychological Bulletin, 77(5), 361-372.

Katz, I., Glass, D.C., Lucido, D., \& Farber, J. (1977). Ambivalence, guilt, and the denigration of a physically handicapped victim. Journal of Personality, 45, 419-429.

Katz, I., \& Hass, R. G. (1988). Racial ambivalence and American value conflict: Correlational and priming studies of dual cognitive structures. Journal of Personality and Social Psychology, 55, 893-905.

Kidder, D. L. (2007). Restorative justice: Not "rights,' but the right way to heal relationships at work. International Journal of Conflict Management, 18, 4-22.

Kottke, J.L., \& Sharafinski, C.E. (1988). Measuring perceived supervisory and organization support. Education and Psychological Measurement, 48, 1075-1079.

Kreiner, G. E., \& Ashforth, B. E. (2004). Evidence toward an expanded model of organizational identification. Journal of Organizational Behavior, 25: 1-27.

Larsen, J.T. (in press). Ambivalence. In R.F. Baumeister \& K.D. Vohs (Eds.), Encyclopedia of social psychology. Thousand Oacks, CA: Sage.

Lewis, J. D., \& Weigert, A. (1985). Trust as a social reality. Social Forces, 63: 967-985.

Liden, R.C., Sparrowe, R.T., \& Wayne, S.J. (1997). Leader-member exchange theory: The past and potential for the future. Research in Personnel and Human Resources Management, 15: 47-119.

Locke, K. D., \& Braun, C. C. (2009). Ambivalence versus valence: Analyzing the effects of opposing attitudes. Social Cognition, 27, 89-104.

Luhrnann, N. (1979). Trust and power. Chichester: Wiley.

Maio GR, Bell D.W., Esses V.M. (1996). Ambivalence and persuasion: the processing of messages about immigrant groups. J. Exp. Social Psychology, 32:513-36.

McCullough, M. E. (2000). Forgiveness as human strength: Theory, measurement, and 
links to well-being. Journal of Social Clinical. Psychoogy. 19: 43-55.

McCullough, M. E. (2001). Forgiveness: Who does it and how do they do it? Current Directions in Psychological Science, 10, 194-197.

McCullough, M. E., Bellah, C. G., Kilpatrick, S. D., \& Johnson, J. L. (2001).

Vengefulness: Relationships with forgiveness, rumination, well-being, and the Big Five. Personality and Social Psychology Bulletin, 27, 601- 610.

McCullough, M. E., Rachal, K. C., Sandage, S. J., Worthington, E. L., Jr., Brown, S. W., \& Hight, T. L. (1998). Interpersonal forgiving in close relationships II: Theoretical elaboration and measurement. Journal of Personality and Social Psychology, 75, 1586-1603.

Mikulincer, M., Shaver, P. R., Bar-On, N., \& Ein-Dor, T. (2010). The pushes and pulls of close relationships: attachment insecurities and relational ambivalence. Journal of personality and social psychology, 98(3), 450.

Mitchell, M.S., \& Ambrose, M.L. (2007). Abusive supervision and workplace deviance and the moderating effects of negative reciprocity beliefs. Journal of Applied Psychology, 92: 1159-1168.

Morrison E.W. \& Robinson, S.L. (1997). When employees feel betrayed: A model of how psychological contract violation develops. Academy of Management Review, 22, 226-256.

Morrow, J., \& Nolen-Hoeksema, S. (1990). Effects of responses to depression on the remediation of depressive affect. Journal of Personality and Social Psychology, 58(3), 519-527.

Nahum-Shani, I., Henderson, M.M., Lim, S., \& Vinokur, A.V. (2014) Supervisor support: Does it buffer or exacerbate the adverse effects of supervisor undermining? Journal of Applied Psychology, 99(3), 484-503.

Nolen-Hoeksema, S. (1991). Responses to depression and their effects on the duration of depressive episodes. Journal of Abnormal Psychology, 100(4), 569-582.

Nolen-Hoeksema, S. (2000). The role of rumination in depressive disorders and mixed anxiety/depressive Symptoms. Journal of Abnormal Psychology, 109(3), 504-511.

Nordgren, L. F., van Harreveld, F., \& van der Pligt, J. (2006). Ambivalence, discomfort, and motivated information processing. Journal of Experimental Social Psychology, 42, 252-258.

Oaten, M., Williams, K.D., Jones, A., \& Zadro, L. (2008). The effects of ostracism on 
self-regulation in the socially anxious. Journal of Social and Clinical Psychology, 27, 471-504.

Oreg, S., \& Sverdlik, N. (2010). Ambivalence toward imposed change: The conflict between dispositional resistance to change and the orientation toward the change agent.

Journal of Applied Psychology.

Orth, U. (2004). Does perpetrator punishment satisfy victims' feelings of revenge? Aggressive Behavior, 30, 62-70.

Padilla, A., Hogan, R., \& Kaiser, R. B. (2007). The toxic triangle: Destructive leaders, susceptible followers, and conducive environments. The Leadership Quarterly, 18,176-194.

Piderit, S. K. (2000). Rethinking resistance and recognizing ambivalence: A multidimensional view of attitudes toward an organizational change. Academy of management review, 25(4), 783-794.

Plambeck, N., \& Weber, K. (2009). CEO ambivalence and responses to strategic issues. Organization Science, 20(6), 993-1010.

Podsakoff, P. M., MacKenzie, S. B., Lee, J. Y., \& Podsakoff, N. P. (2003). Common method biases in behavioral research: A critical review of the literature and recommended remedies. Journal of Applied Psychology, 88, 879-903.

Pratt, M. G., \& Barnett, C. K. (1997). Emotions and Unlearning in Amway Recruiting Techniques Promoting Change through Safe'Ambivalence. Management Learning, 28(1), 65-88.

Chicago

Pratt, M. G., \& Rosa, J. A. (2003). Transforming work-family conflict into commitment in network marketing organizations. Academy of Management Journal, 46 (4): 395 418.

Raudenbush, S. W., \& Bryk, A. S. (2002). Hierarchical Linear Models: Applications and data analysis methods (2nd ed.). Thousand Oaks: Sage Publications.

Robinson, M. D., \& Clore, G. L. (2002). Belief and feeling: Evidence for an accessibility model of emotional self-report. Psychological Bulletin, 128, 934-960.

Rousseau, D. M. (1989). Psychological and Implied Contracts in Organizations. Employee Responsibilities and Rights Journal, 2, 121-139.

Rousseau, D.M. (1995). Psychological contracts in organizations: Understanding written and unwritten agreements. Thousand Oaks, CA: Sage. 
Rudolph, T. J., \& Popp, E. (2007). An information processing theory of ambivalence.

Political Psychology, 28(5), 563-585.

Rusbult, C.E., Verette, J., Whitney, G., Slovik, L., \& Lipkus, I. (1991).

Accommodation processes in close relationships: Theory and preliminary empirical evidence. Journal of Personality and Social Psychology, 60, 53-78.

Schat, A. C. H., Frone, M. R., \& Kelloway, E. K. (2006). Prevalence of workplace aggression in the U.S. workforce: Findings from a national study. In E. K. Kelloway, J. Barling, \& J. J. Hurrell (Eds.), Handbook of workplace violence (pp. 47-89). Thousand Oaks, CA: Sage.

Scott, B. A., \& Judge, T. A. (2006). Insomnia, emotions, and job satisfaction: A multilevel study. Journal of Management, 32, 622-645.

Shanock, L. R., \& Eisenberger, S. (2006). When supervisors feel supported: Relationships with subordinates' perceived supervisor support, perceived organizational support, and performance. Journal of Applied Psychology, 91(3), 689-695.

Shore, L. M., Tetrick, L. E., Lynch, P., \& Barksdale, K. (2006). Social and economic exchange: Construct development and validation. Journal of Applied Social Psychology, 36, 837-867.

Shoss, M.K., Eisenberger, R., Restubog, S. L. D. \& Zagenczyk, T. J. (2013). Journal of Applied Psychology, Vol 98(1), 158-168.

Skarlicki, D. P., \& Folger, R. (1997). Retaliation in the workplace: The roles of distributive, procedural, and interactional justice. Journal of Applied Psychology, 82, 434-443.

Tekleab, A.G., Takeuchi, R. and Taylor, M.S. (2005). Extending the chain of relationships among organizational justice, social exchange, and employee reactions: the role of contract violations. Academy of Management Journal, 48, 146-57.

Tepper, B. J. (2007). Abusive supervision in work organizations: Review, synthesis, and research agenda. Journal of Management, 33, 261-289.

Thau, S., \& Mitchell, M.S. (2010). Self-gain or self-regulation impairment: Competitive tests of the relationship between abuse and deviance through distributive justice perceptions. Journal of Applied Psychology, 95, 1009-1031.

Thompson, M. M., Zanna, M. P., \& Griffin, D. W. (1995). Let's not be indifferent about (attitudinal) ambivalence. In R. E. Petty \& J. A. Krosnick (Eds.), Attitude strength: Antecedents and consequences (pp. 361-386). Hillsdale, NJ: Erlbaum 
Vadera, A. K., \& Pratt, M. G. (2013). Love, hate, ambivalence, or indifference? A conceptual examination of workplace crimes and organizational identification. Organization Science, 24(1), 172-188.

Van Lange, P A. M., Rusbult, C. E., Drigotas, S. M.. Arriaga, X. B., Witcher, B, S.. \& Cox, C. L. (1997). Willingness to sacrifice in close relationships. Journal of Personality and Social Psychology, 72,1373- 1395.

Vidyarthi, P., Liden, R. C., Anand, S., Erdogan, B., \& Ghosh, S. (2010). Where do I stand? Examining the effects of leader-member exchange social comparison on employee work behaviors. Journal of Applied Psychology, 95, 849-861.

Watson, D., \& Clark, L. A. (1994). The PANAS-X: Manual for the positive and negative affect schedule-expanded form. Unpublished manuscript, University of Iowa.

Wegner DM. (1994). Ironic processes of mental control. Psychol. Rev. 101:34-52.

Weigert, A. J. (1991). Mixed emotions: Certain steps toward understanding ambivalence. Albany, NY: State University of New York Press. 
TABLE 1

Means, Standard Deviations, and Correlations Among Study Variables

\begin{tabular}{|c|c|c|c|c|c|c|c|c|c|c|c|c|}
\hline Variable & M & SD & 1 & 2 & 3 & 4 & 5 & 6 & 7 & 8 & 9 & 10 \\
\hline [1] Age & 46.9 & 9.08 & - & & & & & & & & & \\
\hline [2] Gender & 0.52 & 0.49 & $-.13 *$ & - & & & & & & & & \\
\hline [3] Org Tenure & 14.75 & 11.7 & $.63^{* *}$ & $.15^{* *}$ & - & & & & & & & \\
\hline [4] PA & 3.64 & 0.91 & $.47 * *$ & $-.12 *$ & $.28 * *$ & - & & & & & & \\
\hline [5] NA & 1.33 & 0.46 & $-.18 * *$ & $-.12 *$ & $-.25 * *$ & $-.21 * *$ & - & & & & & \\
\hline [6] S-I PCV & 1.17 & 0.83 & $-.33 * *$ & $.10 *$ & $-.37 * *$ & $-.28 * *$ & $.27 * *$ & - & & & & \\
\hline [7] Positive RQ & 3.92 & 0.84 & $.38 * *$ & .02 & $.46^{* *}$ & $.25^{* *}$ & $-.28 * *$ & $-.48 * *$ & - & & & \\
\hline [8] Negative RQ & 1.92 & 0.85 & $-.37 * *$ & .00 & $-.46^{* *}$ & $-.24 * *$ & $.24 * *$ & $.56^{* *}$ & $-.71 * *$ & - & & \\
\hline [9] Ambivalent RQ & 2.45 & 0.89 & $-.29 * *$ & .03 & $-.32 * *$ & $-.18 * *$ & $.13^{*}$ & $.28 * *$ & $-.42 * *$ & $.50 * *$ & - & \\
\hline [10] Rumination & 1.25 & 0.45 & -.12 & -.03 & $-.15^{*}$ & $-.16^{* *}$ & $.45 * *$ & $.42 * *$ & $-.29 * *$ & $.28 * *$ & $.13^{*}$ & - \\
\hline
\end{tabular}

Notes. S-I PCV $=$ supervisor-induced psychological contract violation, RQ = relationship quality, $* * \mathrm{p} \leq .01 * \mathrm{p} \leq .05$ 
TABLE 2

HLM results predicting the moderating effect of relationship quality (positive, negative, ambivalent) on the relationship between S-I PCV and rumination

\begin{tabular}{|c|c|c|c|}
\hline \multirow[t]{2}{*}{ Variable } & \multicolumn{3}{|c|}{ Coefficient } \\
\hline & Model 1 & Model 2 & Model 3 \\
\hline Intercept $\gamma_{00}$ & $1.37^{* *}$ & $1.38^{* *}$ & $1.23^{* *}$ \\
\hline \multicolumn{4}{|l|}{ Controls } \\
\hline Age $\gamma_{10}$ & .00 & .00 & .00 \\
\hline Gender $\gamma_{20}$ & .05 & .05 & .05 \\
\hline Organizational Tenure $\gamma_{30}$ & .00 & -.01 & -.01 \\
\hline Positive Affect $\gamma_{40}$ & $-.08 \dagger$ & $-.08 \dagger$ & -.05 \\
\hline Negative Affect $\gamma_{50}$ & $.11 \dagger$ & $.10 \dagger$ & .08 \\
\hline \multicolumn{4}{|l|}{ Main Effects } \\
\hline S-I PCV $\gamma_{60}$ & & .05 & $.07 \dagger$ \\
\hline Positive Relationship $\gamma_{70}$ & & -.05 & $-.08^{*}$ \\
\hline Negative Relationship $\gamma_{80}$ & & .06 & .06 \\
\hline Ambivalent Relationship $\gamma_{90}$ & & .01 & .01 \\
\hline \multicolumn{4}{|l|}{ Interaction Effects } \\
\hline Positive X S-I PCV $\gamma_{100}$ & & & $-.23 * *$ \\
\hline Negative X S-I PCV $\gamma_{110}$ & & & $-.14 \dagger$ \\
\hline Ambivalent X S-I PCV $\gamma_{120}$ & & & $.22 * *$ \\
\hline Deviance & 217.84 & 205.80 & 178.82 \\
\hline Decrease in deviance & & $12.04 * *$ & $26.98^{* *}$ \\
\hline
\end{tabular}

Notes: $N=271$ (model $1,2 \& 3$ ); $\dagger p<.10 * p<.05 . * * p<.01$

The sample size drops to 271 because S-I PCV items were only completed on days where employees actually reported experiencing a violation; and since rumination required participants to reflect on the previous twenty-four hours, this measure was captured from Day 2 onwards. 
FIGURE 1

The Research Model.

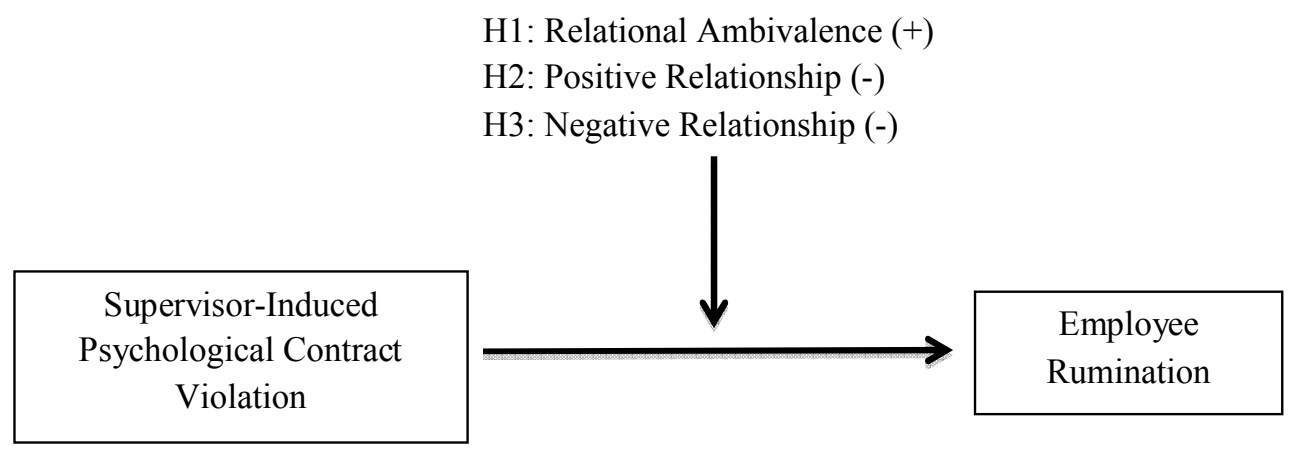


FIGURE 2

The moderating effect of relational ambivalence on the within-group relationship between S-I PCV and employee rumination

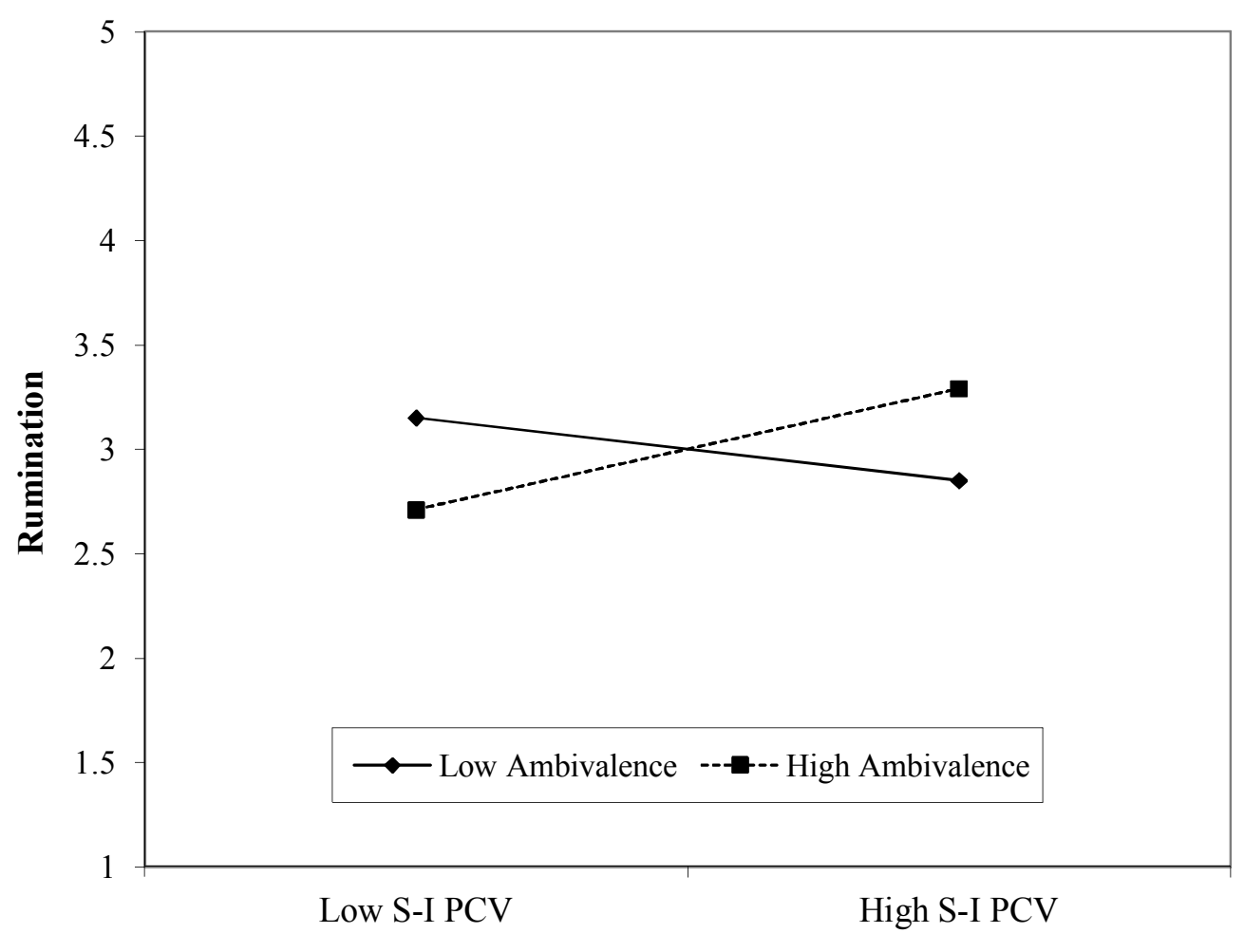


FIGURE 3

The moderating effect of positive relationship quality on the within-group relationship between S-I PCV and employee rumination

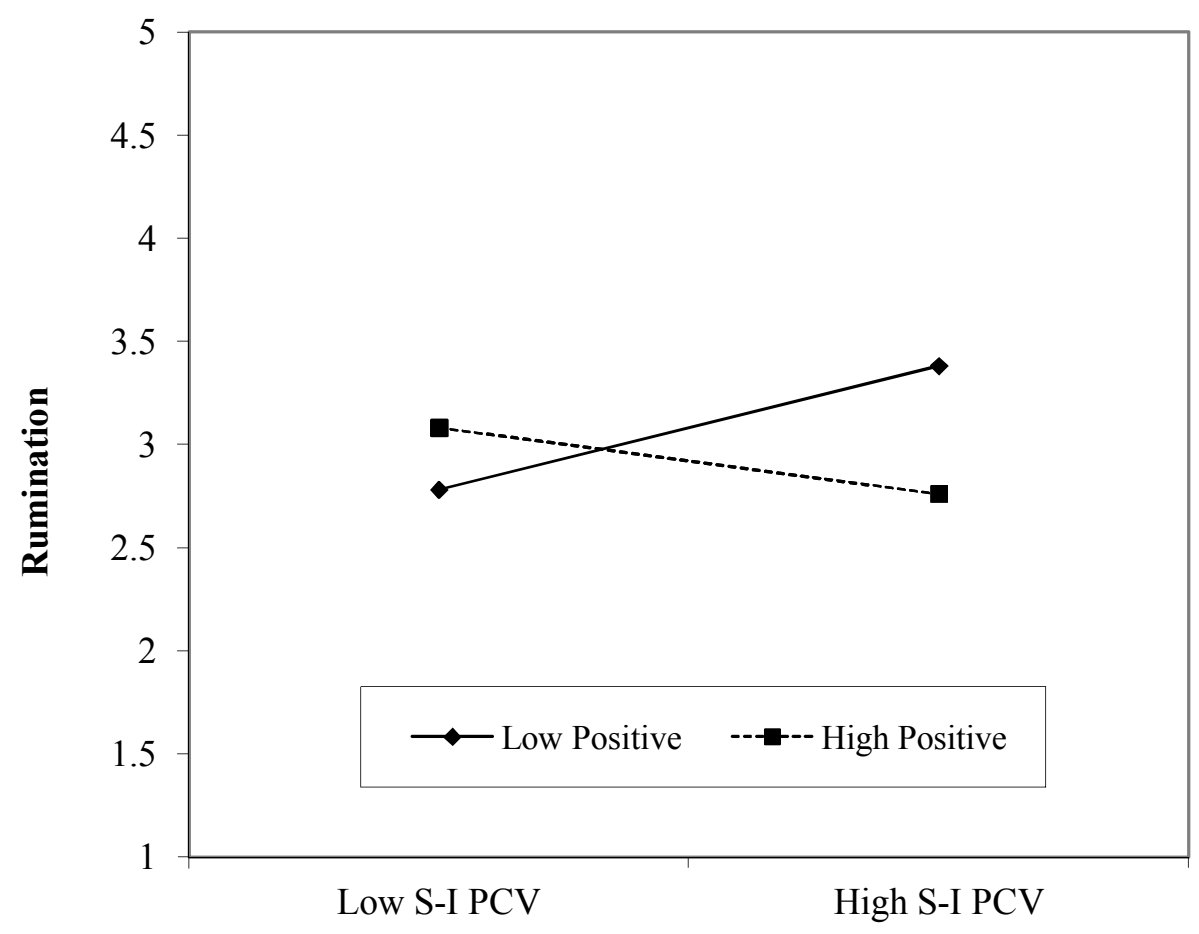


FIGURE 4

The moderating effect of negative relationship quality on the within-group relationship between S-I PCV and employee rumination

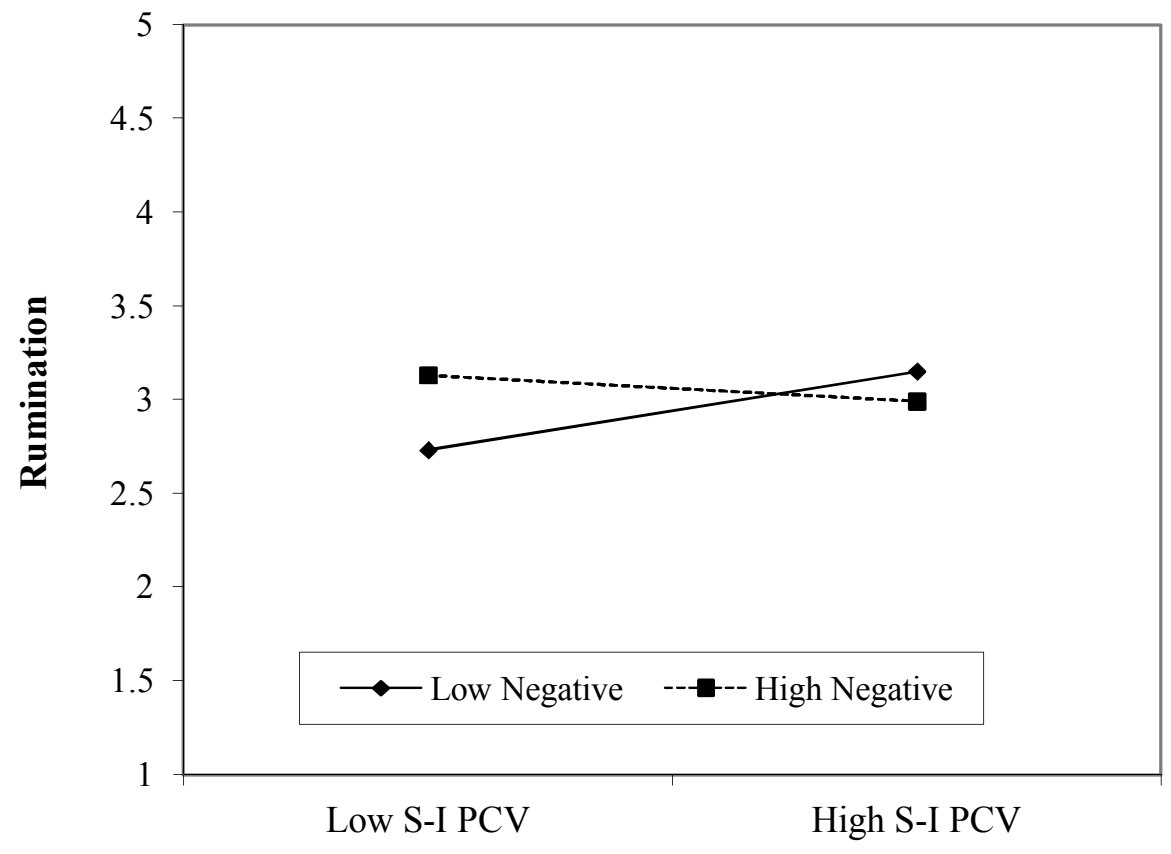

